\title{
The Development of Successive Conjunctions of Chinese
}

\author{
SUN Yong-fang \\ Nanjing Normal University, Nanjing, China
}

\begin{abstract}
The paper explored the development of successive conjunctions from Archaic Chinese to Contemporary Chinese from a macroscopic perspective. Data statistics and diachronic study method were adopted in this paper, and the results indicated that a quantity of new successive conjunctions have been produced both in Archaic Chinese and Mid-ancient Chinese, and at the same time a very large proportion of the old successive conjunctions were superseded by the new. Those which appeared in very few types of corpus and have low frequency of use are more likely to be eliminated. In Contemporary Chinese, the successive conjunction system tends to be stable and concise.

Keywords: successive conjunction, development, diachronic study, Chinese
\end{abstract}

Successive conjunctions are grammatical units that connect words, phrases, and sentences, expressing succession in time or matter. It is an important category of Chinese functional words. So far, scholars have done a lot of important research in this field; however, systematic and macroscopic research on the development of successive conjunctions has not been done yet. Therefore, on the basis of achievements conducted by preceding scholars, this paper will try to comb the system of Chinese successive conjunctions comprehensively, and explore the evolution process, rules, and mechanisms.

\section{The System of Chinese Successive Conjunction}

\section{Successive Conjunction System in Archaic Chinese}

The quantity of successive conjunctions in Archaic Chinese is quite large. Based on the research of Guan (1981), Li (2003), Yang (2003), and Zhang (2001) on grammar of oracle bone inscriptions and bronze inscriptions, and by referring to 12 kinds of literature handed on from ancient times, including 周易 (Zhouyi), 今文尚书 (Jin Wen Shang Shu), 国语 (Guo Yu), 孙子兵法 (Sun Tzu's Art of War), 左传 (Zuo Zhuan), 墨 子 (Mozi), 孟子 (Mencius), 荀子 (Xunzi), 吕氏春秋 (Lv Shi Chun Qiu), 史记 (Shi Ji), 春秋繁露 (Chun Qiu Fan $\mathrm{Lu}$ ), and 淮南子 (Huainanzi), we conclude that the total amount of successive conjunctions in Archaic Chinese is about 76.

Among them, only one was first seen in oracle bone inscription and about 16 were first seen in bronze inscriptions. They are: 乍 (zha), 杫 (zhi), 廼 (nai), 廼乍 (nai zha), 夗 (yuan), 延 (yan), 爱 (yuan), 其 (qi), 乃 (nai), 则 (ze), 用 (yong), 以 (yi), 因 (yin), 而 (er), 安 (an), and 遂 (sui).

The number of successive conjunctions first seen in the handed down documents of the Pre-Qin period is about 42. They are: 若 (ruo), 为 (wei), 斯 (si), 不乃 (pi nai), 丕则 (pi ze), 然 (ran), 如 (ru), 时 (shi), 是 (shi), 䐅 (si), 惟时 (wei shi), 用 (yong), 兹 (zi), 越兹 (yue zi), 而后 (er hou), 然后 (ran hou), 然则

SUN Yong-fang, Ph.D. candidate, School of Literature, Nanjing Normal University, Nanjing, China.

Foundation project: National Social Science Foundation key project "Research on Functional Words in Middle Chinese and Compilation of Functional Words Dictionary in Middle Chinese” (18AYY020). 
(ran ze), 而遂 (er sui), 而又 (er you), 既而 (ji er), 乃今而后 (er jin nai hou), 至于 (zhi yu), 案 (an), 焉 (yan), 即 (ji), 而后 (er hou), 则案 (ze an), 则安 (ze an), 越其 (yue qi), 厥 (jue), 按 (an), 乃遂 (nai sui), 之 (zhi), 自 (zi), 抑 (yi), 兹故 (zi gu), 将 (jiang), 鲜 (xian), 虽 (sui), 于是 (yu shi), 由 (you), and 盖 (gai).

Six successive conjunctions were first seen in Qin-Chu bamboo slips: 辄 (zhe), 於 (yu), 且 (qie), 然而 (ran er), 角 (庸) (yong), and 因而 (yin er).

Twelve successive conjunctions were first seen in the Western Han Dynasty: 已而 (yi er), 后而 (hou er), 于是乃 (yu shi nai), 而乃 (er nai), 至 (zhi), 及其 (ji qi), 及至 (ji zhi), 乃至 (nai zhi), 及至夫 (ji zhi fu), 乃至于 (nai zhi yu), 且夫 (qie fu), 及, and 若夫 (ruo fu).

\section{Successive Conjunction System in Mid-ancient Chinese}

In order to build a more comprehensive successive conjunction system of Mid-ancient Chinese, we selected 13 corpuses for investigation; they are local documents such as: 论衡 (Lun Heng), 太平经 (Tai Ping Jing), 真诰 (Zhen Gao), 抱朴子(内篇) (Baopuzi (inner part)), 世说新语 (Shi Shuo Xin Yu), 搜神记 (Sou Shen Ji), 后汉书 (Hou Han Shu), 宋书 (Song Shu), 梁书 (Liang Shu), and 颜氏家训 (Yan Shi Jia Xun); and Buddhist Sutras translated into Chinese from Eastern Han Dynasty, Wei-Jin-Southern, and Northern Dynasties respectively, and translation classics of Buddhist scripture (本缘部).

According to the 13 kinds of corpus surveyed in this paper, about 103 successive conjunctions were used in Mid-ancient Chinese, of which 26 were produced in Archaic Chinese: 乃 (nai), 则 (ze), 以 (yi), 因 (yin), 而 (er), 然后 (ran hou), 即 (ji), 于是 (yu shi), 遂 (sui), 至于 (zhi yu), 因而 (yin er), 而后 (er hou), 而 乃 (er nai), 辄 (zhe), 至 (zhi), 及 (ji), 如 (ru), 若夫 (ruo fu), 然则 (ran ze), 自 (zi), 若 (ruo), 且 (qie), 然 (ran), 既 (ji), 而后 (er hou), and 之 (zhi).

New-born successive conjunctions in the Mid-ancient Chinese period is about 77, including 34 newly produced in the local documents: 因遂 (yin sui), 遂以 (sui yi), 则夫 (ze fu), 便 (bian), 遂复 (sui fu), 因 复 (yin fu), 乃后 (nai hou), 会 (hui), 因以 (yin yi), 乃且 (nai qie), 又复 (you fu), 因能 (yin neng), 且 复 (qie fu), 乃以 (nai yi), 乃于 (nai yu), 乃而 (nai er), 却 (que), 又且 (you qie), 即则 (ji ze), 则遂 (ze sui), 则以 (ze yi), 随而 (sui er), 辄复 (zhe fu), 乃自 (nai zi), 遂即 (sui ji), 便遂 (bian sui), 便乃 (bian nai), 乃即 (naiji), 至乃 (zhi nai), 更 (geng), 即更 (ji geng), 及以 (ji yi), 至夫 (zhi fu), and 及于 (ji yu).

The remaining 43 were first seen in Buddhist Sutras translated into Chinese in Mid-ancient period: 尔乃 (er nai), 若乃 (ruo nai), 便复 (bian fu), 即便 (ji bian), 便自 (bian zi), 即复 (ji fu), 于是便 (yu shi bian), 于是遂 (yu shi sui), 便即 (bian ji), 便尔 (bian er), 遂便 (sui bian), 方便 (fang bian), 即自 (ji zi), 寻 (xun), 寻即 (xun ji), 寻便 (xun bian), 寻自 (xun zi), 至如 (zhi ru), 至若 (zhi ruo), 若如 (ruo ru), 即寻 (ji xun), 乃便 (nai bian), 遂寻 (sui xun), 寻而 (xun er), 以用 (yi yong), 因则 (yin ze), 因自 (yin zi), 用 自 (yong zi), 辄便 (zhe bian), 辄即 (zhe ji), 辄自 (zhe zi), 仍 (reng), 而自 (er zi), 能自 (neng zi), 有而 (you er), 而便 (er bian), 遂尔 (sui er), 遂乃 (sui nai), 因便 (yin bian), 因尔 (yin er), 因即 (yin ji), 则便 (ze bian), and 若便 (ruo bian).

\section{Successive Conjunction System in Modern Chinese}

From Tang and Song Dynasties to Ming and Qing Dynasties, the time span of Modern Chinese is more than 1,000 years. Therefore, we selected 29 representative corpuses to study the successive conjunctions in this period, they are: 陈书 (Chen Shu), 大唐西域记 (Great Tang Records on the Western Regions), 敦煌变文 (Dun Huang Bianwen), 六祖坛经 (Liu Zu Tan Jing), 祖堂集 (Zu Tang Ji), 景德传灯语录 (Jingde Chuan 
Deng Quotation), 鹤林玉露 (He Lin Yu Lu), 二程语录 (Er Cheng Quotation), 朱子语类辑略 (Excerption of Zhuzi Quotation), 名公书判清明集 (Ming Gong Shu Pan Qing Ming Ji), 宋元话本 (Script for Story Telling of Song and Yuan Dynasty), 全相平话五种 (Five Kinds of Quan Xiang Pinghua), 元典章 (Laws and Regulations of Yuan Dynasty), 西厢记 (Xi Xiang Ji), 新编五代史平话 (Newly Compiled Five Dynasties History Pinghua), 新校元刊杂剧 (Newly Proofreaded Yuan-Dynasty Zaju Plays), 关汉卿杂剧 (Guan Hanqing Zaju), 二刻拍案惊奇 (Er Ke Pai'an Jing Qi), 型世言 (Xing Shi Yan), 醒世恒言 (Xing Shi Heng Yan), 醒世姻缘传 (Xing Shi Yin Yuan Zhuan), 十二楼 (Shi Er Lou), 金瓶梅 (Jin Ping Mei), 水汻传 (Water Margin), 红楼梦 (The Dream of Red Mansion), 儒林外史 (The Scholars), 二十年目睹之怪现状 (The Weird Situation Witnessed in The Past 20 Years), 儿女英雄传 (The Heroic Biography of Sons and Daughters), and 镜花缘 (Jing Hua Yuan).

According to the 29 kinds of Modern Chinese literature referenced in this paper, the total number of successive conjunctions in Modern Chinese is 76, less than that in Mid-ancient times. Among them, 24 were inherited from Archaic Chinese: 则 (ze), 因 (yin), 而 (er), 然后 (ran hou), 于是 (yu shi), 乃 (nai), 以 (yi), 而后 (er hou), 遂 (sui), 至于 (zhi yu), 然则 (ran ze), 若 (ruo), 然 (ran), 然而 (ran er), 因而 (yin er), 即 (ji), 轩 (zhe), 至 (zhi), 及至 (ji zhi), 若夫 (ruo fu), 及 (ji), 爰 (yuan), 如 (ru), 已而 (yi er); and 18 were inherited from Mid-ancient Chinese: 便 (bian), 至如 (zhi ru), 因遂 (yin sui), 若乃 (ruo nai), 遂乃 (sui nai), 便即 (ji bian), 遂即 (sui ji), 及夫 (ji fu), 至若 (zhi ruo), 尔乃 (er nai), 遂复 (sui fu), 而 便 (er bian), 因即 (yin ji), 至乃 (zhi nai), 却 (que), 即便 (ji bian), 于是遂 (yu shi sui), and 则以 (ze yi).

Besides the 42 successive conjunctions inherited from Archaic and Mid-ancient Chinese, 34 are newly produced in Modern Chinese. They are: 至乎 (zhi hu), 便是 (bian shi), 是乃 (shi nai), 是则 (shi ze), 斯乃 (si nai), 若其 (ruo qi), 而便 (er bian), 即而 (ji er), 亦既 (yi ji), 则是 (ze shi), 夫 (fu), 此外 (ci wai), 比 至 (bi zhi), 既然 (ji ran), 既是 (ji shi), 从而 (cong er), 一而 (yi er), 及到 (ji dao), 至到 (zhi dao), 比及 (bi ji), 随后 (sui hou), 那么 (na me), 后 (hou), 次后 (ci hou), 接着 (jie zhe), 那 (na), 那么说 (na me shuo), 那么着 (na me zhe), 可见 (ke jian), 足见 (zu jian), 就 (jiu), 后来 (hou lai), 跟着 (gen zhe), and 于是乎 (yu shi hu).

\section{Successive Conjunction System in Contemporary Chinese}

The successive conjunction system in Contemporary Chinese has a significant reduction in quantity. We referred to works on Modern Chinese grammar of Deng (1983), Zhang (2000), and Zhou (2005), and found that the total number of successive conjunctions in Contemporary Chinese is about 14. They are: 就 (jiu), 便 (bian), 于是 (yu shi), 后来 (hou lai), 接着 (jie zhe), 随着 (sui zhe), 跟着 (gen zhe), 从而 (cong er), 转 而 (zhuan er), 而后 (er hou), 然后 (ran hou), 至于 (zhi yu), 可见 (ke jian), and 于是乎 (yu shi hu).

\section{The Characteristics of the Development of Chinese Successive Conjunctions}

\section{The Process of Continuous Growth and Decline}

From about 76 successive conjunctions in Archaic Chinese to about 14 in Contemporary Chinese, it is not a simple process of continuous deletion, but a process of constantly producing new words and eliminating old ones. Take Mid-ancient Chinese as an example. From Table 1 we can see that of the 103 successive conjunctions in Mid-ancient Chinese, 74.8\% of which are new words, and just 26 (25.2\%) of them were inherited from ancient Chinese, which means that $65.8 \%$ successive conjunctions born in Archaic Chinese were eliminated in Mid-ancient period. 
Table 1

Source Composition of Successive Conjunctions in Different Periods

\begin{tabular}{llllllll}
\hline Period & Tource & From Archaic Chinese & $\%$ & $\begin{array}{l}\text { From Mid-ancient } \\
\text { Chinese }\end{array}$ & $\%$ & $\begin{array}{l}\text { From Modern } \\
\text { Chinese }\end{array}$ & $\%$ \\
\hline Archaic Chinese & 76 & 76 & $100 \%$ & & & & \\
Mid-ancient Chinese & 103 & 26 & $25.2 \%$ & 77 & $74.8 \%$ & & \\
Modern Chinese & 76 & 24 & $31.6 \%$ & 18 & $23.7 \%$ & 34 & $44.7 \%$ \\
\hline
\end{tabular}

\section{From Monosyllable to Disyllable}

In oracle bone inscription and bronze inscription, monosyllabic successive conjunctions occupied an absolute predominance. However, the number of disyllabic successive conjunctions has increased significantly in the Pre-Qin handed down literature. After the Western Han Dynasty, the number of new disyllabic successive conjunctions was much higher than that of new monosyllabic successive conjunctions, as can be seen Table 2. Many scholars believe that Chinese vocabulary has experienced the evolution from monosyllable to polysyllable, as Yin, Long, and Zhao (2016, p. 10) pointed out that monosyllabic words are the main form of word formation before the third century, and the trend of polysyllabic words has begun; in Mid-ancient Chinese, compound word formation gradually developed as the main form of word formation, and polysyllabic words increased substantially.

Table 2

Syllable Situation of New Successive Conjunctions in Different Periods

\begin{tabular}{llllllll}
\hline \multicolumn{1}{c}{ Syllable } & Total & Monosyllabic & $\%$ & Disyllable & $\%$ & Polysyllabic & $\%$ \\
\hline Oracle Bone and Bronze Inscriptions & 16 & 15 & $93.8 \%$ & 1 & $6.2 \%$ & 0 & 0 \\
Pre-Qin Handed-Down Documents & 48 & 27 & $56.3 \%$ & 20 & $41.7 \%$ & 1 & $2 \%$ \\
Western Han Dynasty & 12 & 1 & $8.3 \%$ & 8 & $66.7 \%$ & 3 & $25 \%$ \\
Mid-ancient Chinese & 77 & 6 & $7.8 \%$ & 69 & $89.6 \%$ & 2 & $2.6 \%$ \\
Modern Chinese & 34 & 4 & $11.8 \%$ & 28 & $82.4 \%$ & 2 & $5.8 \%$ \\
\hline
\end{tabular}

\section{Increased Frequency of Use}

Compared with oracle bone inscriptions, the number of successive conjunctions in bronze inscriptions of Zhou Dynasty increased, but the frequency of use was still low. Guan (1981, p. 190) inspected 208 important bronze inscriptions of the Western Zhou Dynasty, found 160 use cases of 用 (yong), and the use cases of other successive conjunctions ranged from 1 to 7 (with a total of 26). Compared with the corpuses before the Warring States Period, both the number and the frequency of use of successive conjunctions increased greatly after that, as can be seen from Figure 1: 


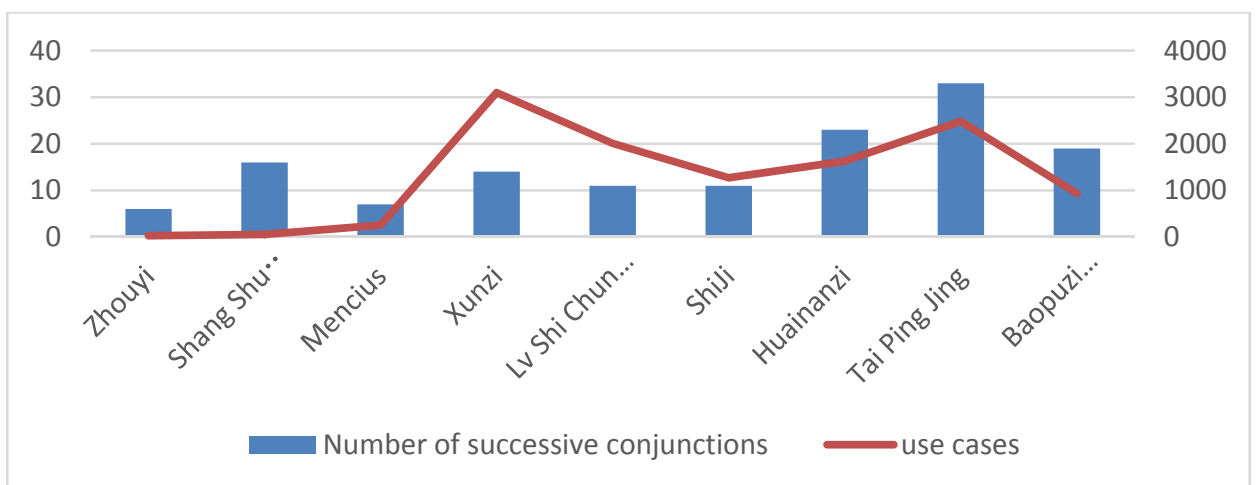

Figure 1. The development tendency of Chinese successive conjunctions in some important corpuses (from Zhou Dynasty to Wei-Jin Period).

\section{The Commonly Used Successive Conjunctions Are Relatively Stable}

The total amount of successive conjunctions in ancient Chinese is large, but status of their use is different. We judge whether a word is commonly used by two criteria: the type of documents it appears and its frequency of use. We found that the types of corpus used of many successive conjunctions are limited, and the commonly used successive conjunctions have strong stability.

According to statistics, only seven words appeared in more than half of the corpuses examined in this paper in Archaic Chinese, and 11 in Mid-ancient Chinese, five in Modern Chinese. The most commonly used successive conjunctions from Archaic Chinese to Modern Chinese are: 则 (ze), 乃 (nai), 遂 (sui), 而 (er), 以 (yi), and 然后 (ran hou). Besides, their frequency of use as successive conjunctions is much higher than others. For example, the analysis of Yin's study (2008) showed that there are 14 successive conjunctions in 吕 氏春秋 ( $L v$ Shi Chun Qiu), and the total use cases of successive conjunctions is 3,100. However, among them, 而 (er) has 1,219 cases, 以 (yi) 414, and 则 (ze) 267, the total use cases of these three words accounting for 61.2\% of the total use successive conjunctions in 吕氏春秋 ( $L v$ Shi Chun Qiu).

\section{Conclusion}

Wang (2005, p. 144) mentioned that the main successive conjunctions in ancient times were 则 (ze) and 而 (er), and the Chinese successive conjunctions listed by Ota (2003, pp. 296-298) are: 就 (jiu), 嗣后 (si hou), 于是 (yu shi), 然后 (ran hou), 这才 (zhe cai), and 那么 (na me). However, as mentioned above, the successive conjunctions in Chinese history are far more than those listed above.

In the development process of Chinese successive conjunctions, some words produced in Archaic Chinese but were not among the most commonly used may flourished in the Mid-ancient Ages, such as 因 (yin) and 于是 (yu shi); in comparison, some words that commonly used in the Archaic Chinese may be weakened gradually, such as 然则 (ran ze); some words may be flourished in just one period but were not commonly used in other periods, like 即 (ji) and 遂复 (sui fu); they flourished in the Mid-ancient Ages only.

Uncommonly used successive conjunctions may become commonly used, but more often, they will be eliminated. What makes them different? According to our survey, it is decided by whether they are widely used or not and the frequency of their use. Words with many kinds of corpus and relatively high frequency will exist steadily and remain in the next period. The successive conjunctions appeared in more than five corpuses in the Archaic Chinese will be retained in 100\% of the Mid-ancient Chinese and Modern Chinese. However, $90 \%$ of the successive conjunctions appeared in only one corpus investigated in this paper will be eliminated. 
Obviously, there is a significant positive relationship between the variety of corpus a word appears and whether the word is retained in future generations.

\section{References}

Deng, F. N. (1983). 汉语语法新编 (New edition of Chinese grammar). Changsha: Hunan Education Press.

Guan, X. C. (1981). 西周金文语法研究 (A study on the grammar of Jinwen in Western Zhou Dynasty). Beijing: Business Press. Li, X. (2003). 殿墟卜辞语法 (Oracle grammar of Yin Ruins). Xi’an: Shanxi Normal University Press.

Ota, T. (2003). 中国语历史文法 (Chinese historical grammar). Beijing: Peking University Press.

Wang, L. (2005). 汉语语法史 (History of Chinese grammar). Beijing: Business Press.

Yang, F. B. (2003). 尉墟甲骨刻辞词类研究 (A study on the parts of speech of the Oracle Bone Inscriptions in Yin Ruins). Guangzhou: Huacheng Press.

Yin, G. G. (2008). 《吕氏春秋》词类研究 (A study of the parts of speech in Lv Shi Chun Qiu). Beijing: Business Press.

Yin, G. G., Long, G. F., \& Zhao, T. (2016). 汉语史纲要 (第二版) (Outline of Chinese language history) (2nd ed.). Beijing: Renmin University Press.

Zhang, Y. S. (2000). 现代汉语虚词 (Functional words in Modern Chinese). Shanghai: East China Normal University Press.

Zhang, Y. J. (2001). 甲骨文语法学 (Oracle grammar). Shanghai: Xuelin Press.

Zhou, G. (2005). 现代汉语多方位研究 (Multidimensional study of Modern Chinese). Chengdu: Bashu Press. 